Historic, Archive Document

Do not assume content reflects current scientific knowledge, policies, or practices. 



\title{
Bulletin No. 2.
}

\section{8.}

\section{TUSKRGR NORMAL AND INDUSTRIAL RISTYYUN,}

\author{
TUSKBGER, ALABAMA,
}

ExperimentStation.

Experiments with Sweet Potatoes.

G. W. CARVER.

Tuskbgie, Ala.:

Normal School Steam Press.

1898. 



\section{The The Tuskegee Agricultural Experiment Station.}

\begin{tabular}{l|l}
\hline BulhotiN No. 2. | & MaY, 1898. \\
\hline
\end{tabular}

EXPERIMENTS WITH SWEET POTATOES.

G. W. CARVER.

As the question of potash, phosphoric acid and nitrogen is of so much importance to southern agriculture, the German Kali Works of New York, very kindly donated the following kinds and amounts of fertilizers to be used on sweet potatoes:

Acid Phosphate, ...................... $600 \mathrm{lbs}$

Nitrate of Soda, ....................

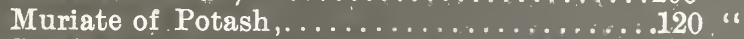

Sulphate of Potash, ................

Total.................. $\overline{968}$ "

The soil used in this experiment was that of an old, worn-out field, that had been "cropped" year after year un'der the exhaustive tenant system, until it was deficient physically, mechanically. and chemically. So much so that cow peas would not grow successfully upon it.

As to situation, it might be termed upland, very light and sandy in texture, with yellow clay sub-soil. There was a small excess of sand, which is favorable to the production of the sweet potato.

\section{PREPARATION OF THE SOIL.}

Blount's Two-horse Daisy Turning Plow was used and the earth turned upside-down (not set up on edge) to a depth of eight or nine inches. A good harrow was now put upon it. and it was harrowed both ways thoroughly; then re-plowed with a one-horse plow, harrowed and re-harrowed, until practically every clod was mashed and a deep, mellow seed bed made.

This eight or nine inches of mellow soil permitted the water to penetrate it quickly, and very materially increased its capacity for holding water, and almost completely overcame the destructive washes which are so frequent in soils of this character, caused by 



\section{BOARD OF REGENTS.}

President, Wm. LeRoy Broun, ..............Auburn, Alabama.

HoN. I. F. CULVER, .................. Montgomery, Alabama.

MR. GEORES IV. CAMPBELL,

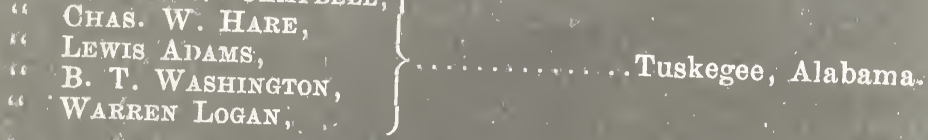

\section{STATION STAFF.}

GRORGE W. GARVER, M. Ag. ................... Director. CHARLES W. Grbene,$\ldots \ldots \ldots \ldots \ldots \ldots \ldots \ldots \ldots \ldots$.

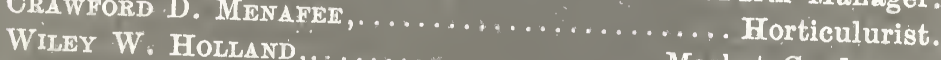

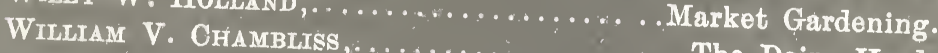

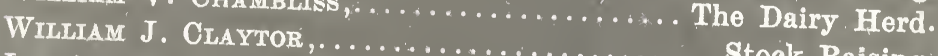
LYNA A BURKS $, \ldots, \ldots \ldots \ldots \ldots \ldots \ldots \ldots \ldots \ldots \ldots \ldots \ldots \ldots \ldots$. Ribrarian. 

the shart-sighted method of merely skimming the surface to a depth of two or three inches.

Aside from this, much fertility that had become useless to the plant from the impaction of the soil and the depth to which the fertilizers had sunken into it, was regained.

These fertilizers were brought near the surface, where the action of the sun, wind, rain and the different climatic changes might readily fit them for plant food.

The potashes and phosphates were applied broad-cast at once and harrowed in.

\section{CAUTION.}

All mineral fertilizers; such as potash, phosphoric acid and lime, should be applied as nearly as possible as follows, all other things being equal: Potash six weeks, phosphoric acid four weeks; before planting anything upon it; especially in their less soluble forms.

In heavy clay soils, situated so they do not wash, both of these substances are better applied in the fall, but where the soil is light and sandy, with no clay sub-soil, like much of our Southern soils, it is best applied as first recommended. Lime should be applied in the fall. Great care must be used in the application of all these fertilizers, as phosphoric acid has a tendency to leach in very sandy soils, and thus be lost. Kanit and other forms of potash contain more or less chlorine, which is injurious to the growth of many plants. This latter substance readily leaches out when placed in the soil ; the potash does not, but remains there as available plant food:

These three fertilizers have but little if any effect upon the immediate crop when applied as a top dressing.

All high-grade nitrates, such as nitrate of soda, should be applied as a top dressing and cultivated in lightly, as they dissolve readily and sink into the soil and are carried away by heavy rains and in a number of different ways, but may be saved, in the main, as the plant has power to retain and utilize them.

\section{CLIMATIC CONDITIONS.}

Rain had not fallen in any appreciable amount in three weeks, rendering the soil dry to a depth of three inches; in addition, the days were extremely hot and cloudless.

\section{SETTING.}

A hole was dug in the earth sufficient to hold two or three gallons of water, a thin mortar was made, using clay for this purpose, as it holds moisture longer and adheres to the plants better. The root end of each plant was dipped into this thin mud. A bunch of 50 or 100 dipped thus, were ready to be set. This took more work than that required by a favorable season. One boy with a hoe went ahead and scraped the dry earth away down to that which was moist, another followed and dropped the well muddied slips from the wet cloth in which they were carried; a third boy quick- 

Iy made a hole in the moist earth and carefully set the plant, pressing the earth gently but firmly around the roots, and finished by drawing the fine dry earth over this, to conserve (save) the moisture and prevent hardening or baking around the plants, as it otherwise would have done.

With this treatment but few died, although not a drop of rain fell for a period of seventeen days after setting. (The plants were neither shaded nor watered.) The slips were'pulled from the bed just the same as for ordinary planting. Owing to reasons beyond our control, the plants were not set until June 6 .

\section{CULTIVATION.}

The nitrate of soda was applied June 28 ; sown broad-cast and plowed in very lightly with a four-toothed cultivator. The same afternoon a very heavy rain fell.

The last plowing was made' July 19 , with a diamond scooter, three inches in width, this being the only plow that could be used, as the vines on plots 2 and $7 \mathrm{a}$ bad completely hidden the earth.

In every manipulation, great care was taken to keep the ground practically level. This, in connection with a good dust mulch, conserved (saved) the moisture in the land until the vines covered the ground sufficiently to perform this same office, except on plots 1, 1a, 8 and 8a. These might have been plowed the entire season without interference from vines, as. they at no time hid more than one-third of the plot upon which they grew.

\section{DESCRIPTION OF PLOTS.}

The plots were all one-tenth of an acre in size, and the exact amount of fertilizer indicated in the diagram put upon each one. (See plots, pages 6 and 7 .) Paths four feet wide separated one plot from another. The plowing, setting and after-cultivation was exactly the same for each plot. There were fifteen rows in each plot and sixty-five plants set in each row. 

PLAN OF EXPERIMENT.

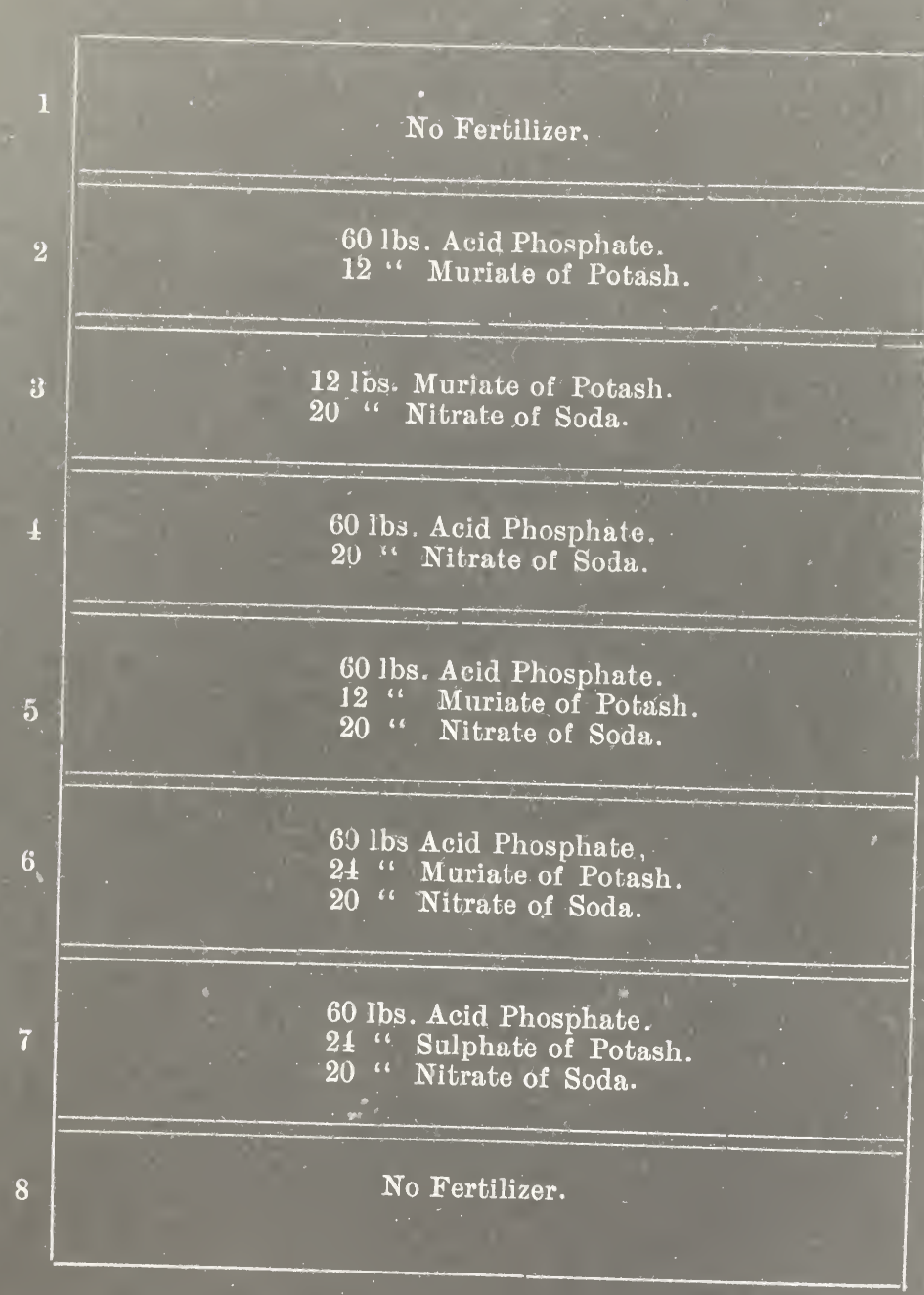



PLAN OE EXPERIMENT.

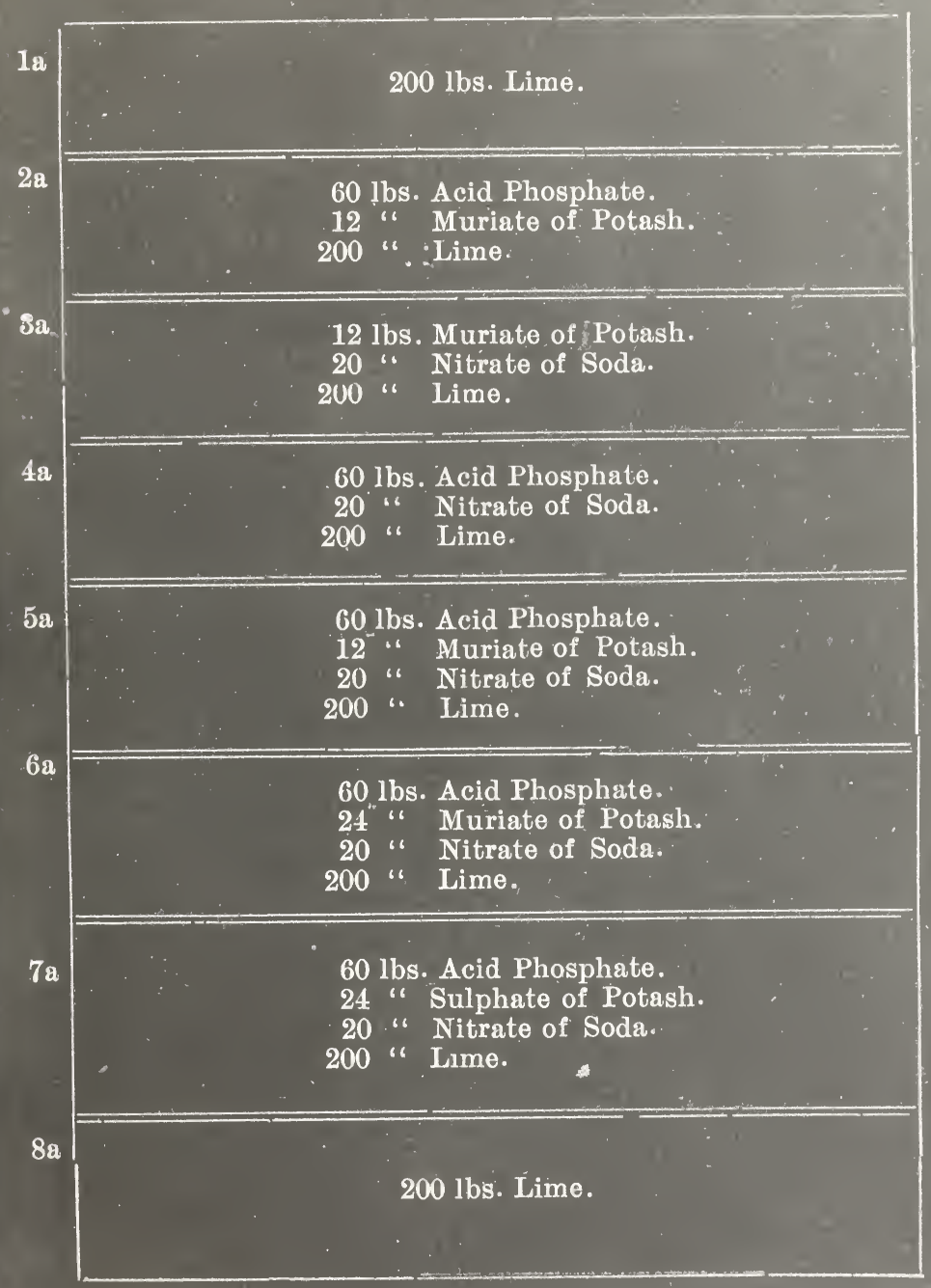





\section{YIELD OF PLOTS PER ACRE.}

Since this bulletin has been issued some local changes have been made, hence the change in the table.

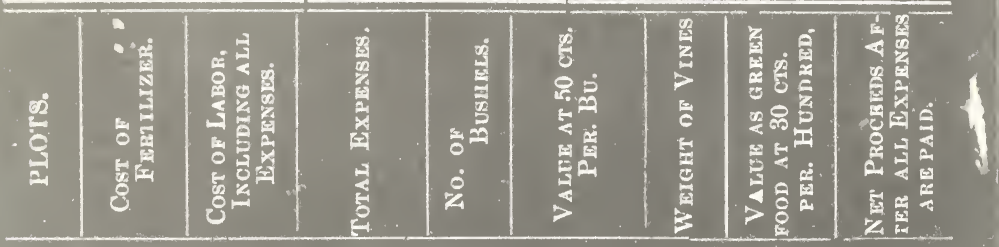

\begin{tabular}{|c|c|c|c|c|c|c|c|c|c|c|}
\hline & & & & & & & I.BS. & Dul's. & $\$$ & Crs \\
\hline 1 & 00.0 & $\$ 12.00$ & $\$$ & 12.00 & 40 & \& $10.00^{\circ}$ & 1500 & $\$ 4.500$ & 2 & 50 \\
\hline $2 \pi$ & $-\$ 6.60$ & 12.00 & & 18.60 & 266 & 133.00 & 12000 & 36.110 & 150 & $40^{\circ}$ \\
\hline 3 & 8.00 & 12.00 & & 20.00 & $165 \frac{1}{2}$ & 82.75 & 2000 & 6.00 & 68 & 75 \\
\hline 4 & 8.60 & $12.00^{\circ}$ & & 20.60 & 120 & 60.00 & 2100 & 6.30 & 45 & 70 \\
\hline 5. & 11.60 & 1200 & & 23.60 & 170 & 85.00 & 2100 & 6.30 & 67 & 70 \\
\hline 6 & 14.60 & 12.110 & & 26.60 & 171 & 85.50 & 2100 & 6.30 & 65 & 20 \\
\hline 7 & 14.60 & 1200 & & 2660 . & 180 & 90.00 & 2180 & 6.54 & 69 & 94 \\
\hline 8 & 00.00 & 12.00 & & 12.00 & 40 & $10.00^{\text {s }}$ & 1500 & 450 & 2 & 50 \\
\hline $1 \mathrm{a}$ & 8.50 & 12.00 & & 20.50 & $95 \frac{1}{2}$ & 47.75 & 1870 & 5.61 & 32 & 86 \\
\hline $2 a$ & -15.10 & 1200 & & 27.10 & $91 \frac{1}{2}$ & 4575 & 1860 & 5.58 & 25 & 23 \\
\hline $3 \mathrm{a}$ & -16.00 & 1200 & & 28.50 & 62 & 31.00 & 1690 . & 5.07 & 7 & 57 \\
\hline $1 \mathrm{a}$ & -17.10 & 12.00 & & $29.10^{\circ}$ & 96 & 48.00 & 1870 & 5.61 & 24 & 51 \\
\hline $5 \mathrm{a}$ & -20.10 & 12.00 & & 32.10 & 142 & 71.00 & 2000 & 6.00 & 44 & 90 \\
\hline $6 \mathrm{a}$ & $-\quad 23.10$ & 12.00 & & 35.10 & 168 & 81.50 & 2100 & 6.30 & 52 & 70 \\
\hline $7 \mathrm{a}$ & 23.10 & 12.00 & & 35.10 & 204 & 102.00 & 11290 & 3887 & 100 & 77 \\
\hline $8 \mathrm{a}$ & $8.5 . J$ & 12.00 & & 20.50 & 951 & 47.75 & 1870 & 5.61 & 32 & 86 \\
\hline
\end{tabular}

The potatoes were so small and inferior that 25 cts. per. $\mathrm{Bu}$. had to be taken.

T The mark - (minus) is used in the table, to call attention to the great contrast in the kind, quantity and cost of fertilizer used. 

HARVDSTING.

The potatoes were harvested December 3 , and yielded per acre as shown by the table. (See page 8.)*

One can readily see that plot No. 2 yielded by far the most potatoes with the least expense and, of course, brought in the largest net returns (\$121); that is clear profit after all expenses
were paid.

thas True the fertilizers cost $\$ 38$, but the heavy yield of vines acty paid this $\$ 86$ in valuable stock food, a matter which too many of our farmers overlook. The vines fed green to dairy cows will greatly improve the quantity of milk and the quality of butter.

The vines are very succulent and hard to dry, turning quite black, but cattle eat them with an apparent relish. They are said to be worthless for silage purposes, as they become quite slick and; in many cases, very offensive in smell, rendoring them worthleśs for food.

To the casual observer the rate per hundred on these vines will doubtless appear abnormally high, but if one considers the almost total absence of highly nutritious green forage at the time of potato harvest, 30 cents per 100 will not appear out of reason ; the dietetic effect on stock is especially desirable at this season of the year.

it is also noticeable that no nitrogen was used on Plot 2, and that the potatoes were of a fine, marketable size and remarkably uniform; almost totally void of strings and inferior ones. (See cut, page 11.)

This is of special importance, when we consider that many millions of pounds of some fertilizer containing nitrogen, for which the purchaser must pay 17 cents or more per pound for every pound of actual nitrogen purchased.

Neither owner nor renter can afford to apply this expensive plant food where it is not needed, although much of this is being done every year.

*Note.-I AM INDEBTED TO MR. C. W. GREENE FOR THE CAREFUL, PAINSTAKING MANNER IN WHICH EVERY OPERATION WAS PERFORMED. 

PLOT 1.

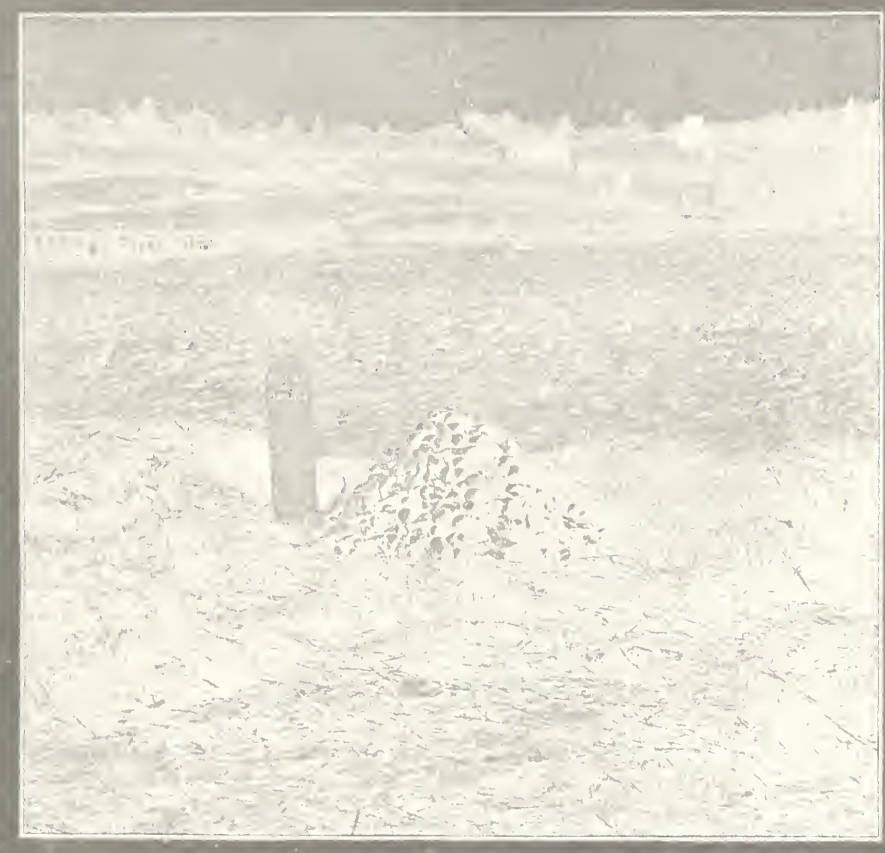

NO FERTILIZER.

Yield 40 bushels per acre.

Sold for 25 cents por bushels-so inferior.

Net gain $\$ 2.50$. 

PLOT 2.

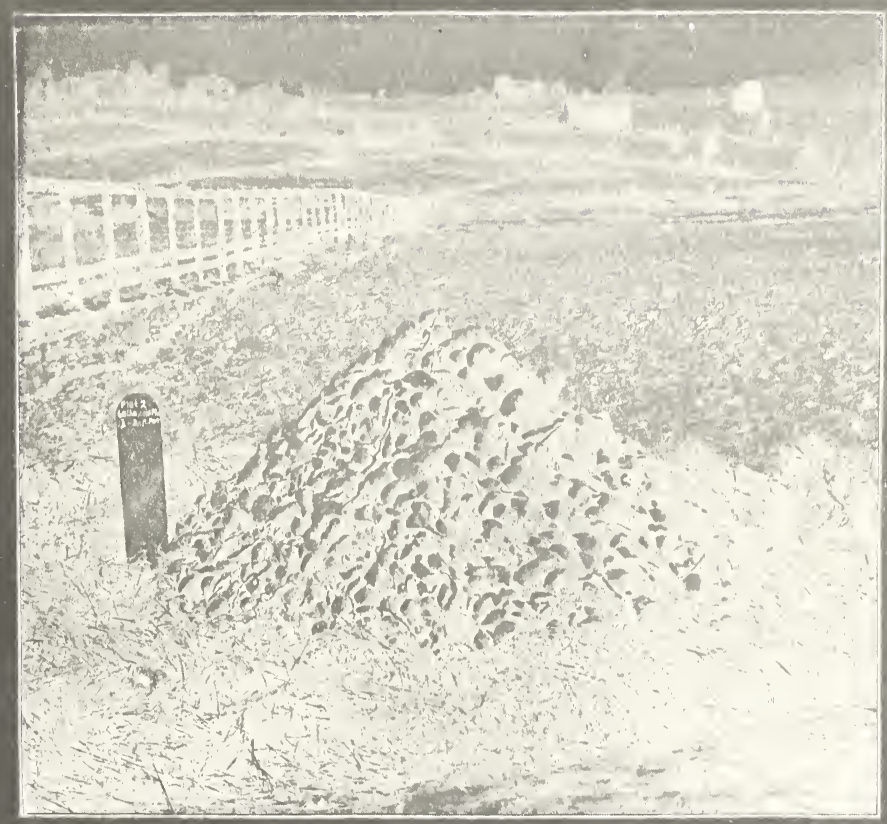

60 LBS. ACID PHOSPHATE.

12 " MURIATE OF POTASH.

Yield 266 bushels per acre. Sold at 50 cents per bushel. Net gain $\$ 121, ;, .<0$ 


pa

$\checkmark$ 
PLOT 3.

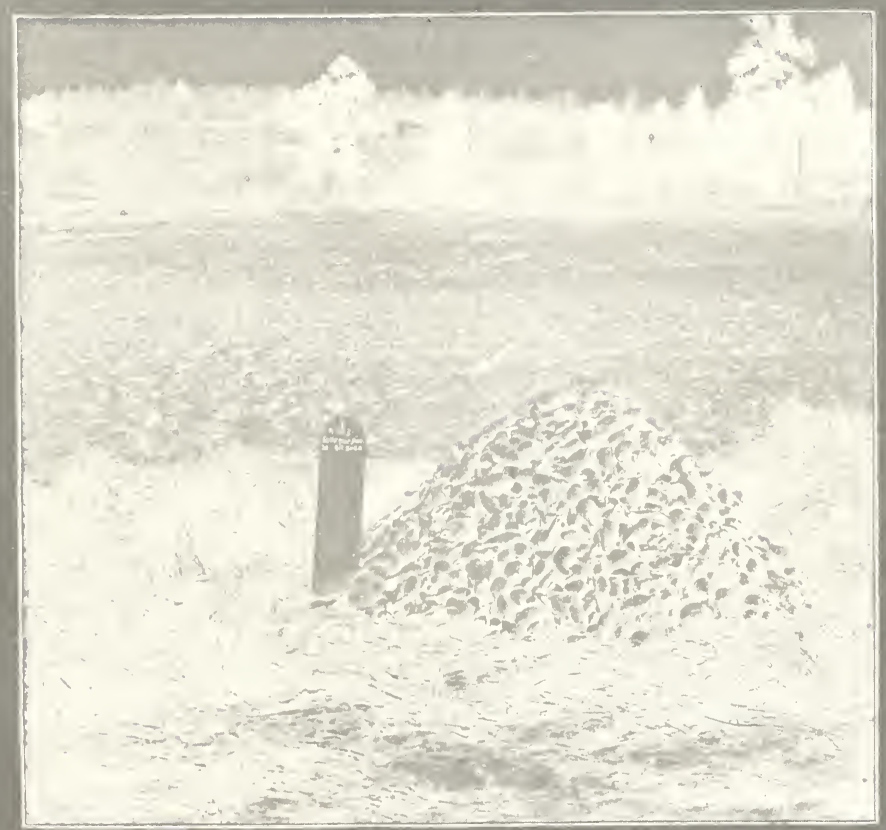

12 lbs. Muriate of Potash.

20 " Nitrate of Soda.

Yield 165.5 bushels per acre.

Sold at 50 cents per bushel.

Net gain $\$ 87.75 .68 .75$ 

It is almost folly to attempt a comparison between Plots 1 and 2 , the cuts and figures speak as loudly as words in favor of proper fertilization.

Plots $3,7 \mathrm{a}$ and $8 \mathrm{a}$ are interesting and worthy of study. (See pages 12,13 and 14.) Also note the kind; quantity and cost of fertilizers, and the amount made. You will, therefore, notice ${ }_{6}$ by referring to page 8 , that some of the plots had as high as $\$ 26, \$ 68$, $\$ 59, \$ 88, \$ 89$, and $\$ 95$, worth of fertilizers (reckoned per acre) put upon them, and by the minus sign before the numbers, shows that the cost of production was that much greater than the product wass worth. Rak d.

\section{PLOT 7A.}

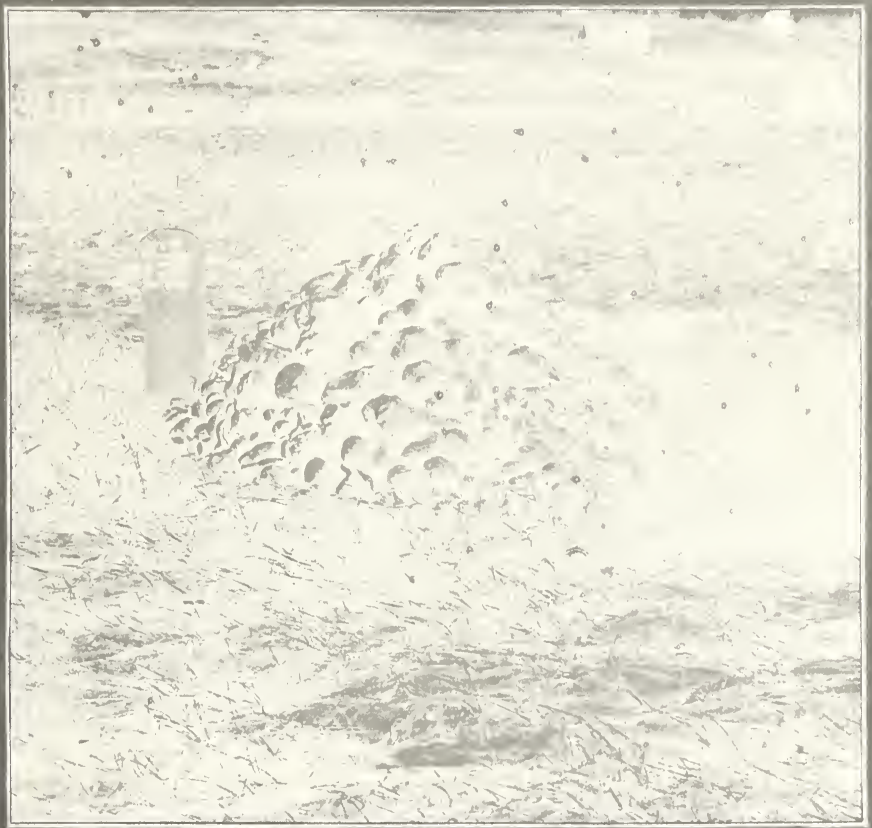

60 lbs. Acid Phosphate.

24 " Sulphate of Potash.

20 " Nitrate of Soda.

200 " Lime.

Yield 204 bushels per acre.

Sold at 50 cents per bushel.

Net gain $\$ 28.87 ., 18,>$. 



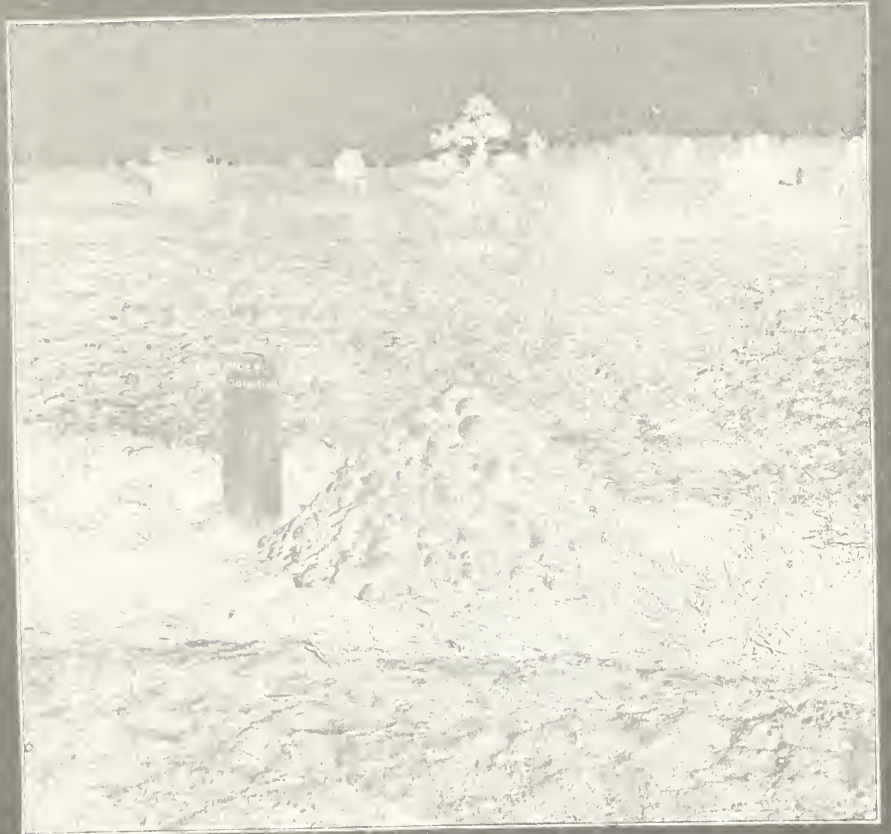

200 lbs, Lime.

Yield 95.5 bushels per acre.

Sold at 50 cents per bushel.

Net gain $\$ 21.36 .327 c^{6}$

\section{EXPLANATORY.}

Since local' conditions are so variable and such wide differences in the cost of transportation, nothing more than an approximate value can be placed upon the fertilizing materials upon the market.:-

As a rule, in and around Tuskegee, nitrogen, phosphoric acid and potash may be had at the following prices. (This is for high-grade fertilizers):

Nitrogen $\ldots \ldots \ldots \ldots \ldots \ldots \ldots 16 \frac{1}{2}$ cents per pound.

Phosphoric Acid........... 5 " " " "

Potash as Muriate.......... "5 " " " "

Potash as : Sulphate........ 5 " " " "

Note.-We are greatly indebted to the donors of the fertilizers for the five cuts. 


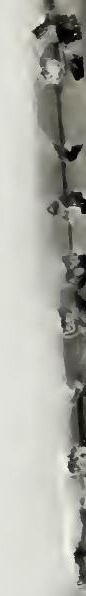


KDEPING QUALITIES.

With the great number of plots fertilized so differently, it suggested to us that a test of the keeping qualities would not only be interesting, but valuable; accordingly, the test was made by selecting a half-bushel of potatoes from each plot. These were placed in a cool, dry, well-ventilated room. They were handled carefully from time to time, removing all that showed evidence of decay. I really saw no appreciable difference, (as about the same number from each plot kept nicely until time for bedding in the spring,) except plots $1,8,7 \mathrm{a}$ and 2 .

The potatoes from 1 and 8 seemed to dry up, being so small I had but few of them by bedding time. Those of 7 a being very large, coarse and full of water, decayed badly until well cured; after that they kept quite well. I kept one nine-pound potato from this plot until late in the summer.

Plot 2 kept much the best and were decidedly the best sellers, being so well developed and uniform.

SUMMARY.

In summing up and drawing conclusions from this experiment, I think it quite safe to conclude that, with the proper manage-

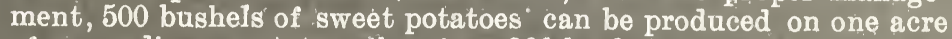
of our ordinary potato soils ; since 266 bushels were produced under the following trying conditions :

First.-Abnormally poor soil, physically, mechanically and chemically.

Second.-Owing to unavoidable reasons, the fertilizers could not be applied at the right time, which decreased the yield.

Third.-The plants were set quite three weeks late.

Fourth.-The potato crop was practicallv a failure almost all over the entire South; the average yield in this section being about 37 bushels per acre.

NOTE.

This bulletin should be carefully studied by all who grow or expect to grow potatoes, and the following rules observed:

(a) Prepare the ground well, by turning it over from eight to nine inches deep with a good two-horse plow, harrowing and pulverizing well.

(b) Plant, practically flat, in dry soils, as high ridges dry out too quickly.

(c) Fertilize well with potash and phosphates, using but little nitrogen ; constantly remembering that the preparation of the soil and the after cultivation (which must be shallow) has quite as much to do with successful potato growing as the fertilizers used.

(d) And that potash and phosphates are indispensible to the highest development of the potato and all root crops.

(e) That our average upland soils will be benefitted by a light dressing of lime-say 200 pounds to the acre.

(f) Sulphate of potash seemed to be of no special value over the muriate.

(b) That heavy dressings of fertilizers containing nitrogen, are not necessary. 
